REVISTA DE ESTUDOS EM ARTES CÊNICAS

E-ISSN 2358.6958

\title{
Tradições inventadas e criação de espaço de pertencimento: Uma revisão de literatura
}

\author{
Adailson Costa dos Santos \\ Jorge das Graças Veloso
}

Para citar este artigo:

SANTOS, Adailson Costa dos; VELOSO, Jorge das Graças. Tradições inventadas e criação de espaço de pertencimento: Uma revisão de literatura. Urdimento Revista de Estudos em Artes Cênicas, Florianópolis, v. 3, n. 42, dez. 2021.

doi DOl: http:/dx.doi.org/10.5965/1414573103422021e0201

Este artigo passou pelo Plagiarism Detection Software| iThenticate 


\title{
Tradições inventadas e criação de espaço de pertencimento: Uma revisão de literatura ${ }^{1}$
}

\author{
Adailson Costa dos Santos² \\ Jorge das Graças Veloso ${ }^{3}$
}

\begin{abstract}
Resumo
O presente trabalho teve como intuito apresentar as ideias iniciais que estão sendo desenvolvidas em uma pesquisa realizada no âmbito do Doutorado em Artes Cênicas da UNB. A pesquisa teve como objetivo expor as concepções da Festa dos Bonecos Gigantes, que acontecem no município de Taquaruçu, no Tocantins, para defender a hipótese de que a mesma se constitui como uma tradição inventada, a qual foi pensada com o intuito de designar um espaço de pertencimento até então inexistente para seus fazedores. Aqui, foram discutidos conceitos de diversos campos de conhecimento para fundamentar primeiro o conceito de pertencimento enquanto uma instituição ontológica e inerente ao ser humano em sociedade. Posteriormente, foi discutido o conceito de tradições inventadas, e por fim, apresentado o lócus de pesquisa e a afetação deste trabalho: a festa supracitada. É possível compreender a Aldeia TabokaGrande como um espaço inventado para se sentir pertencente.
\end{abstract}

Palavras-chave: Tradição. Taquaruçu. Bonecos Gigantes.

${ }^{1}$ Revisão ortográfica e gramatical do artigo realizada por Ingrid Cruz do Nascimento. Licenciada em Letras e doutoranda em Linguística pela Universidade Federal da Paraíba. E-mail para contato: ingridcruznascimento@gmail.com.

2 Doutorando em Artes Cênicas pela Universidade de Brasília UnB). Mestrado em Performances Culturais pela Universidade Federal de Goiás (UFG). Bacharel e Licenciado em Teatro pela Universidade Federal da Paraíba (UFPB). Professor EBTT do Curso de Licenciatura em Teatro e da Especialização em Arte Educação do Instituto Federal do Tocantins. adailson_costa15@hotmail.com

9 http://lattes.cnpq.br/0352379347160471 (iD) https://orcid.org/0000-0002-0969-4024

${ }^{3}$ Pós-Doutor em Arte e Cultura Visual pela Universidade Federal de Goiás (UFG). Doutor em Artes Cênicas pela Universidade Federal da Bahia (UFBA - 2005). Mestre em Artes Cênicas pela mesma universidade (2001). Graduação em Comunicação Social, pelo Centro Universitário de Brasília (1978) e Licenciatura Plena em Educação Artística: Artes Cênicas, pela Faculdade de Artes Dulcina de Moraes (2006). Professor adjunto II na Universidade de Brasília (UnB). jorgegracaveloso@gmail.com

http://lattes.cnpq.br/7206112236857233 (1) https://orcid.org/0000-0002-4714-9596 
Invented traditions and creation of belonging space: A literature review

\begin{abstract}
The present study aimed to present the initial ideas being developed in a research carried out in the scope of the PhD in Performing Arts at UNB. The research aimed to expose the conceptions of the Festa dos Bonecos Gigantes, which take place in the municipality of Taquaruçu, in Tocantins, to defend the hypothesis that it constitutes an invented tradition, which was designed in order to designate a space of belonging hitherto non-existent for its makers. Here, concepts from different fields of knowledge were discussed to first support the concept of belonging as an ontological institution inherent to human beings in society. Afterwards, the concept of invented traditions was discussed, and finally, the research locus and the affectation of this work were presented: the aforementioned party. It is possible to understand the Aldeia TabokaGrande as a space invented to feel belonging.
\end{abstract}

Keywords: Tradition. Taquaruçu. Giants Puppets.

\title{
Tradiciones inventadas y creación de espacios de pertenencia: Una revisión de la literatura
}

\section{Resumen}

El presente trabajo tuvo como objetivo presentar las ideas iniciales que se están desarrollando en una investigación realizada en el ámbito del Doctorado en Artes Escénicas de UNB. La investigación tuvo como objetivo exponer las concepciones del Festival de Marionetas Gigantes, que se realiza en el municipio de Taquaruçu, en Tocantins, para defender la hipótesis de que constituye una tradición inventada, la cual fue diseñada con el propósito de designar un espacio de pertenencia hasta ahora no -existente para sus creadores. Aquí, se discutieron conceptos de diferentes campos del conocimiento para apoyar en primer lugar el concepto de pertenencia como institución ontológica inherente al ser humano en la sociedad. Posteriormente se discutió el concepto de tradiciones inventadas y finalmente se presentó el locus de investigación y la afectación de este trabajo: la fiesta mencionada. Es posible entender la Aldeia TabokaGrande como un espacio inventado para sentir pertenencia.

Palabras clave: Tradición. Taquaruçu. Marionetas Gigantes. 


\section{O que nos afeta?}

Esta pesquisa debruça-se sobre os conceitos de diversas áreas do conhecimento para revisar a concepção que estas possuem acerca da noção de pertencimento dos sujeitos. Também são abordados os conceitos que são absorvidos no que diz respeito às práticas das tradições inventadas. O objetivo dessas revisões é dialogar com as falas do criador acerca do que é chamado de "local de afetação" da pesquisa: a Festa dos Bonecos Gigantes da Aldeia TabokaGrande, no distrito de Taquaruçu, no Tocantins. Pretende-se, desse modo, demonstrar como o Mestre Wertemberg Nunes, por meio do processo de invenção de uma tradição, construiu um espaço de pertencimento.

Antes de adentrar na constituição da hipótese, é importante definir o local de onde se é afetado para esta questão: esta pesquisa é construída dentro do campo da Etnocenologia. O leitor poderá notar que, durante o texto, evita-se a utilização de termos, tais como: ponto de vista, pode-se ver, visto, enxergar. Isso se dá a partir das mais recentes discussões realizadas pelo grupo de estudos em Etnocenologia, da Universidade Federal de Brasília, as quais alertam para a necessidade de desviar o "olhar" para fora dessa estrutura que coloca a visão no centro teórico.

Abre-se aqui, portanto, a discussão sobre ponto de afetação e de percepção, uma vez que, desviando a linguagem do campo macro da visão, englobam-se todos aqueles que não a utilizam como mecanismo de percepção do mundo. Além disso, existem momentos nas vivências no campo das culturas, humanidades e artes que sequer são percebidos e/ou explicáveis pela visão. É sobre sentir, se afetar e perceber, mais do que somente ver. De forma alguma isso é uma crítica a qualquer "ponto de vista": o que se discute é apenas uma outra forma de se afetar com o mundo.

\section{Afetação 1 - Etnocenologia}

Agora, volta-se para entender o nosso primeiro ponto de afetação que é a 
teoria da Etnocenologia. Esse campo de estudo surge no cenário mundial em 1995, após o Colloque de Fondationdu Centre International d'Ethnoscénologie, realizado em Paris. O colóquio reuniu artistas e pesquisadores de várias partes do mundo e, como resultado, foi lançado, no ano citado, o Manifesto da Etnocenologia. A Etnocenologia surge, então, em meio ao espírito de mudança do final do século XX e adentra no campo das etnociências com o intuito de ampliar "os horizontes teóricos da pesquisa científica e artística, mais especificamente o trabalho dos pesquisadores dedicados às artes do espetáculo" (Bião, 2011, p.109).

Todavia, a Etnocenologia não se propõe apenas ao estudo daquelas artes mais academicamente estabelecidas, uma vez que no espectro dessa ciência não são

considerados somente o teatro, a dança, o circo, a ópera, o happening e a performance. Inclui-se também outras práticas e comportamentos humanos espetaculares organizados, dentre os quais alguns rituais, fenômenos sociais extraordinários e até mesmo formas de vida cotidiana quando estas são pensadas enquanto fenômenos espetaculares (Bião, 2011, p.109).

Nesse sentido, o conceito da área de estudo em voga sentido, este conceito propõe uma compreensão que comunga os pensamentos dos estudos culturais com os estudos das artes da cena, sendo estas "cenas" ampliadas para os diversos espaços de atuação humana, tais como festas, reuniões, manifestações tradicionais, ou seja, as manifestações da cultura como um todo.

O que diferencia a Etnocenologia dos demais campos dos estudos culturais, da antropologia teatral ou da performance é, principalmente, o fator paradigma/paradoxo. Enquanto as ciências no geral possuem seus paradigmas e, ao analisar a realidade social, aplicam este paradigma sobre ela, a Etnocenologia se propõe ao paradoxo, repleto de contradições, fluido, desestabilizante. A diferença paradigma/paradoxo se dá quando o fundamento da Etnocenologia é "valorizar os princípios característicos de cada forma, prática e comportamento espetacular, sem visar a identificação de um conjunto de princípios universais" (Bião, 2011, p.110-111). Nesse sentido, pode-se dizer que a Etnocenologia é uma ciência que se propõe a desestabilizar os campos de conhecimento estabelecidos, 
as certezas da pesquisa, as posições hierarquizadas e as conceituações externas e em via de mão única.

Embora não tenha uma relação direta, dada a diferença temporal, a perspectiva lexical da Etnocenologia corrobora diretamente com as teorias decoloniais emergentes nos últimos anos no que diz respeito ao problema da colonialidade do saber (Ballestrin, 2013). O ente a quem foi dado o direito de falar, classificar e nomear é sempre um outro e este outro quase sempre é o outro europeu. O outro que se debruça sobre o mundo, aplicando ora sua visão paradigmática, onde apenas seus léxicos são válidos, ou então, assumindo uma falsa noção de neutralidade em seu discurso, cuja denominação é dada pelo filósofo colombiano Castro-Gómez (2005) como "hybris del punto cero". Neste punto cero o pesquisador no campo se coloca e ignora o local do qual ele, o pesquisador, fala, suas apreensões e o quanto, na maior parte das vezes, seu pensamento é repleto de eurocentrismo (Castro-Gómez, 2005).

O campo da Etnocenologia tenta andar na contramão desse posicionamento eurocêntrico proposto pelo discurso e pelos léxicos de pesquisa. Para tanto, é forte o pensamento de que a melhor forma de tratar o recorte que se estuda é utilizando-se das formas e das palavras que seus próprios fazedores utilizam. Essa questão é apontada pelo Professor Armindo Bião, um dos fundadores da Etnocenologia e principal nome do campo no Brasil, quando ele diz:

Prefiro, também, para designar o artista do espetáculo, ou o participante ativo da forma - ou arte - espetacular, palavras como aquelas usadas pelos próprios praticantes dos objetos de nossos estudos [...] prefiro sinceramente isso a usar outras palavras, como as que já foram sugeridas por outros [...] prefiro, sempre, usar espetáculo, função, brincadeira, jogo ou festa, conforme quem vive e faz, denomina aquilo o que faz e vive (Bião, 2009. p.40).

Sendo assim, compreende-se que a Etnocenologia busca desde sua origem um processo de diálogo entre os colaboradores da pesquisa, sem uma tentativa paradigmática de sobrepujar a fala de um (pesquisador) à vivência do outro (fazedor). A Etnocenologia como campo teórico trabalha sob o constante "trepidar das placas terrestres", uma vez que se insere no espaço do roçar, da fricção, do 
atrito e do incômodo. Este é o local de onde surgem as inquietações desse campo teórico.

Não pautada em paradigmas, dado que sua principal bandeira é esta, a perspectiva da etnociência é absorver dos campos teóricos e filosóficos circunvizinhos metodologias e práticas que corroborem com as descobertas a que se propõe. Nesse sentido, o espaço híbrido, um dos principais elementos metodológicos da etnociência, parece ser quase sem metodologia. Todavia, o espaço híbrido é extremamente potente, pois nele é permitido trabalhar com diferentes possibilidades teóricas, desde a Economia até a Antropologia, sem se fundamentar em apenas um discurso.

É importante salientar que o paradoxo é a escolha do campo, bem como a ampliação, ou a centralização dos discursos dos colaboradores da/na pesquisa. Em vista disso, o intuito da Etnocenologia não é escutar apenas o discurso do pesquisador que foi a campo e tirou suas conclusões. O texto, a fala, os termos e os conceitos surgem no espaço de diálogo com os fazedores e a voz deste pesa dentro da pesquisa. Essa introdução ao campo ajuda a conduzir o leitor para a compreensão do local de onde percebemos e nos afetamos pelos conceitos e pelas falas dos fazedores da festa, as quais estarão presentes durante o texto.

\section{Afetação 2 - Pertencimento}

Retomando a hipótese defendida, é importante iniciar a discussão apresentando o que se compreende aqui como o status do pertencer para que, posteriormente, se possa relacionar esta noção com a de manifestação inventada. Pertencer, do latim pertinescere, dialoga com toda uma gama de sentimentos e necessidades dos sujeitos de se fazerem participantes e/ou pertencentes a algo ou algum lugar. Este algo pode ir desde uma tribo local à sensação de pertencimento do todo nacional, sendo inclusive o pertencimento uma das bases para o sentimento de nacionalismo, agrupamentos religiosos e até mesmo a sensação patriótica provocada pela guerra (Maia, 2019).

Muito mais do que um termo que se aproxima da ideia de posse, propriedade ou domínio (Pertencer, 2020), "pertencer” aqui é compreendido na sua face verbal 
como movimento, portanto, se fazer pertencente, ou se sentir participante de algo. Para muitas comunidades os silenciamentos de espaços são recorrentes, por isso com verbo se fazendo pertencente a este grupo é reafirmar as origens, os preceitos, as características e as crenças de sua tribo.

O conceito de tribo aqui surge a partir da compreensão do sociólogo francês Michel Maffesoli, que apresenta sua tese de que a pós-modernidade traz consigo noções arcaicas que remoldariam este tempo em consonância com as transformações psico-sócio culturais. Ele diz que:

Se a modernidade se encarna nas instituições e nas grandes narrativas de que são portadoras, a pós-modernidade dá importância às tribos, aos espaços que ocupam, às formas de socialidade que aí se desenvolvem. Dá-se um novo alento aos mitos que a visão linear do progressismo asfixiou, à bricolage mitológica (Maffesoli, (2010, p.21).

Vê-se, então, uma retomada dessas noções arcaicas, denominadas assim pelo próprio Maffesoli, como uma emergência de pertença dos seres sociais que coabitam na pós-modernidade. Essa necessidade altera as microestruturas do cotidiano que refletem diretamente nas compreensões da macroestrutura das nossas sociedades pós-modernas.

O autor segue apontando que os tribalismos são um fenômeno originalmente cultural, antes mesmo de se apresentarem nos espaços políticos, econômicos ou até mesmo no aspecto social (Maffesoli, 2006). Nesse sentido, para essas tribos contemporâneas "pouco importa o projeto econômico, político, social, a ser realizado. Elas preferem entrar no prazer de estar junto" (Maffesoli, 2006, p.07). Desse modo, percebe-se que as tribos modernas estão fortemente ligadas à necessidade "arcaica" de pertencer, de estar em conjunto e de compartilhar ideias. Por fim, Maffesoli nos brinda com a compreensão de que o "o tribalismo lembra, empiricamente, a importância do sentimento de pertencimento, a um lugar, a um grupo, como fundamento essencial de toda vida social" (Maffesoli, 2006, p.11).

As teorias das afetações e percepções sobre o mundo passam a ser permeadas pelo campo da Etnocenologia, pelo seu jeito de aproximar-se do campo, pela escuta desses colaboradores e pelas noções com as quais eles se 
identificam. Para a Etnocenologia, que bebe da teoria sociológica de Maffesoli, é muito cara a noção teórica da identificação como um local fluido do sujeito frente a sociedade. Segundo Armindo Bião (2009, p.38), a identificação deve ser entendida como uma "categoria de momentâneo reconhecimento do sujeito, em parte ou no todo". Ela estaria em contraposição com a ideia fixa de identidade, em que o sujeito é percebido por apenas uma face frente ao local no qual ele se identifica.

Seguindo o caminho de pensamento da noção de identificação dos sujeitos associada à compreensão do tribalismo, os grupos na pós-modernidade já não podem mais ser entendidos como fixos, ou seja, não é mais possível estabilizar a percepção porque os próprios pertencimentos são móveis. Portanto, a noção do pertencer não mais determina os sujeitos, pois estes podem mover-se entre espaços e tribos de acordo com as suas percepções e afecções. Tais noções móveis e de autonomia dos entes estão presentes na compreensão de uma sociedade da autonomia, na qual é preciso viver ou criar os significados.

Uma sociedade autônoma, uma sociedade verdadeiramente democrática, é uma sociedade que questiona tudo o que é pré-determinado e, assim, libera a criação de novos significados. Em tal sociedade, todos os indivíduos são livres para escolher criar para suas vidas os significados que quiserem (e puderem) (Castoriadis, 1991 apud Bauman, 2001).

É desde a compreensão da necessidade de invenção de significados para a vida que se discute a noção da construção de locais de pertencimento. Tal compreensão amalgama estes pensamentos para se relacionar com o anseio dos sujeitos de inventar, quando não encontram, os seus locais de pertencimento. Graça Veloso (2018), discutindo acerca dos espaços da capital federal Brasília, e suas implicações para os sujeitos e fazedores artísticos, principalmente os dos ritos espetaculares, compreende o sentimento de pertença como uma necessidade tanto de reunir-se como de identificar-se.

Esses ritos espetaculares, então, trazem o sentimento de que pertencem a um determinado lugar, onde podem, por desejo próprio, criar, recriar ou fazer permanecer suas práticas expressivas. O que é sempre alentador para as pessoas comuns, para os homens e as mulheres que

${ }^{4}$ Maffesoli (2006) discute a ideia de identidade e de identificação. 
compreendem o significado de ouvir a grama crescer, vivendo o ordinário de seu cotidiano sempre feito dos melhores sabores. Esses melhores sabores são feitos de saberes trocados naquilo que dá sentido às suas vidas, na capacidade de reinventar práticas de si baseadas no que de verdade lhes importa: o fundante e intransferível direito de estar juntos (Veloso, 2018, p.19).

O sentimento de pertença gera nos sujeitos um movimento de reconhecimento frente aos setores da vida, seja nos limites da construção subjetiva ou na prática cotidiana nos espaços físicos de fato. As práticas retroalimentam-se do sentimento e constituem esses espaços inventivos do pertencer.

Além dessa noção de invenção do sentimento de pertença que cria locais de pertencimento, pode-se dialogar com as noções do economista Hassan Zaoual, que propõe a noção de sítios simbólicos de pertencimento. Em uma crítica à sociedade denominada pelo próprio Zaoual como "economia da violência", pautada num extremo globalizar e em um constante sobrepujar das sociedades e culturas em desenvolvimento, pondo em evidência uma característica universalizante nesta. Zaoual propõe a noção de homo situs, como a ideia de que o homem não possui em si características universalizantes, mas que este constrói suas racionalidades no nível social em um determinado lugar, ou seja, in situ.

Considerando essa perspectiva, a noção de sítio simbólico de pertencimento atua como um espaço de aquilombamento, de resistência. A Aldeia em Taquaruçu é a materialização de um locus, um espaço para se fazer pertencente a algo. Zaoual segue conceituando sítio simbólico de pertencimento como:

De modo essencial, cada sítio é uma entidade imaterial que impregna o conjunto da vida em dado meio. Ele possui um tipo de caixa preta feita de crenças, mitos, valores e experiências passadas, conscientes ou inconscientes, ritualizadas. Ao lado deste aspecto feito de mitos e ritos, - sítio possui também uma caixa conceitual que contém seus conhecimentos empíricos e/ou teóricos, de fato, um saber social acumulado durante sua trajetória. Enfim, os atores em dada situação operam com sua caixa de ferramentas que contém seu saber-fazer, técnicas e modelos de ação próprios ao contexto (Zaoual (2006, p.36).

Nesse ínterim, dialoga-se na apreensão destes dois conceitos. De um lado, a 
necessidade de constituir-se um espaço físico ou simbólico para sentir-se pertencente, ou seja, produzir elementos que simbolicamente nos conecte a algo ou algum lugar. Do outro lado, a ideia do aquilombar-se da forma como Bárbara Souza (2008, p.106) apresenta, sendo este, portanto, "uma ação contínua de existência autônoma frente aos antagonismos que se caracterizam de diferentes formas ao longo da história".

Assim sendo, tanto a Aldeia TabokaGrande possui seu caráter simbólico para os participantes, quanto demonstra um forte movimento de aquilombamento cultural no distrito de Taquaruçu. Esse movimento de aquilombar-se e encontrar espaço de pertencimento proporcionou a festa dos Bonecos Gigantes, com todas as míticas e mitologias em volta dos bonecos e da festa.

Outro ramo das ciências que também trata das características do pertencer é a Psicologia Ambiental (ramo da Arquitetura relacionado com a Psicologia Espacial). Em seus estudos sobre as percepções dos espaços sociais e físicos dos prédios e construções, a Psicologia Ambiental discute o conceito de apropriação como um aspecto de significação do espaço por parte dos sujeitos, pois "na apropriação, o sujeito interage dialeticamente com o entorno, o que resulta numa transformação mútua" (Mourão e Cavalcante, 2006). Dessa maneira, os sujeitos modificam o espaço ao redor para afinar as noções de pertencimento àquele espaço. Segundo o psicólogo Enric Pol (2006, p.145):

As ações sobre o espaço não se constituem, portanto, somente em atos cognitivos ou materiais, mas em atos de investimento emocional, momento em que o agir e o sentir encontram-se em plena sintonia. [...] Pela apropriação, o sujeito sente que de alguma forma está ligado ao lugar, e que este the pertence, mesmo que dele não tenha a posse legal. A relação vem a ser recíproca, pois ele também pertence ao lugar.

Aqui propõe-se uma transferência de sentido quando se pensa nos espaços ontológicos e em como nestes "espaços" os seres constroem, modificam e agem para se sentirem pertencentes. Nesse sentido, a construção de um lugar de pertencimento parte da necessidade de os seres se encontrarem em tribos. Contudo, em alguns momentos, as tribos existentes não são suficientes. Logo, é preciso modificar os "espaços" por meio de um processo de apropriação, gerando 
o contexto de pertencimento desejado.

As pessoas, individualmente ou de forma coletiva, necessitam identificar territórios como próprios para construir sua personalidade, estruturar suas cognições e suas relações sociais, e ao mesmo tempo suprir suas necessidades de pertença e de identificação (Pol, 1996 apud Mourão e Cavalcante, 2006).

É a partir dessas construções que se passa a discutir o campo de pesquisa e o papel dos colaboradores de pesquisa nesses contextos. Seguem-se, então, as discussões sobre a Aldeia TabokaGrande e a festa dos bonecos gigantes como uma tradição inventada com o objetivo de construir um local de pertencimento do Mestre Wertemberg Nunes e seus familiares.

\section{Afetação 3 - A Aldeia TabokaGrande}

A Aldeia TabokaGrande, coordenada pelo Mestre Wertemberg Nunes, realiza diversas atividades cênicas, festivas e ritualísticas durante o ano. O principal mote da Aldeia TabokaGrande é a brincadeira dos Bonecos Gigantes ${ }^{5}$ e toda a mística derivada e/ou desenvolvida nessa brincadeira6.

O Projeto Aldeia TabokaGrande foi idealizado e é coordenado pelo teatrólogo, produtor e pesquisador cultural e Mestre Wertemberg Nunes ${ }^{7}$ que, em 2001, iniciou o projeto dos Bonecos Gigantes no distrito de Taquaruçu. O referido projeto parte da inquietação em desenvolver atividades que auxiliassem o resgate de uma

\footnotetext{
${ }^{5}$ É entendido dentro do meio dos bonequeiros que o boneco não é um objeto inanimado que toma vida ao ser levado à cena ou a festa, mas que ali, no momento em que ele é guardado, sua energia continua viva e ele continua sua "brincadeira" ou vida em outro local. Por esse motivo, neste projeto me proponho a tratar os Bonecos Gigantes sempre com letra maiúscula, tal como substantivos próprios, para retirá-los desse local de objeto inanimado e trazê-los para dentro da pesquisa enquanto colaboradores dela.

6 Esta pesquisa centra-se no campo teórico-metodológico das teorias etnocenológicas, e, portanto, corroborando com o pensamento de um de seus fundadores, o Prof. Armindo Bião, da nomenclatura a ser utilizada nas pesquisas etnocenológicas, diz que "prefiro, sempre, usar espetáculo, função, brincadeira, jogo ou festa, conforme quem vive e faz chama aquilo que faz e vive” (Bião, 2011, p.121). Assim, será usada, durante a escrita da tese, a forma como os fazedores denominam suas atividades, seja ela uma brincadeira, uma festa, uma performance, uma encenação, etc. Entretanto, este projeto encontra-se em fase de organização, sem que tenha havido tempo para afinar nos discursos dos colaboradores esses termos. Nesse ínterim, escolheu-se utilizar termos mais próximos das festas tradicionais, tais como brincadeira e festa, partindo da premissa de que o termo "performance" não abarque a complexidade dessa manifestação.

7 O Mestre Wertemberg Nunes é nascido em Gurupi no antigo norte Goiano, hoje conhecido como Tocantins. Pesquisador de Culturas tradicionais trabalha há mais de 30 anos com estudos de bonecos gigantes. Desde 2001, fundou a Aldeia TabokaGrande no Tocantins.
} 
percepção antropológica e mitológica do povo da terra, bem como de suas relações possíveis com os elementos da natureza na região de Taquaruçu (Bezerra, 2013).

A aldeia, enquanto espaço físico, desenvolve diversas ações durante o ano, que vão desde as vivências com os bonecos gigantes, as músicas e as histórias criadas pelos próprios fazedores da festa até as trilhas que podem ser feitas dentro do espaço de natureza preservada do local. A maior parte dos elementos que acontecem na festa têm um forte caráter singular, alicerçados nas capacidades do multiartista Wertemberg, que transita na construção de todos os bonecos, no toque dos instrumentos, na composição das músicas e dramaturgias das festas, na inserção e retirada de personagens, ou seja, nas invenções, as quais são diversas.

Os Bonecos Gigantes da Aldeia TabokaGrande e sua festa no distrito de Taquaruçu possui uma mística, uma dramaturgia e uma forma de bem-fazer muito próprio, seja por uma questão estética dos bonecos, seja por toda a mística e significado por detrás de cada um dos personagens da festa.

São, ao todo, nove bonecos "oficiais" no cortejo festivo, cada um deles tendo sua origem e referência dentro da brincadeira. Pode-se organizar os bonecos em dois grupos. O primeiro grupo dos bonecos é composto de quatro personagens que possuem referência direta à cosmovisão do povo tocantinense, sendo eles: o Amarelo, que representa as pessoas do lugar e atua como um líder ou comandante da festa; o Cacau, cuja origem do seu nome deriva da palmeira e do fruto do babaçu e representa as belezas da natureza, principalmente aquelas presentes na região do distrito e do cerrado tocantinense; a Mãe Bá, que simboliza as tradições, e, por fim, a Boiuna, que simboliza a água, bem como, a força feminina (Bezerra, 2013). Nesses quatro personagens originários e místicos da brincadeira, nota-se as referências dadas pelo Mestre Wertemberg Nunes no que diz respeito à compreensão da mitologia da natureza, com personagens que representam elementos desta composição, a saber: os seres humanos, a flora, a terra e a água, respectivamente. 
O segundo grupo é composto por cinco bonecos que são denominados Galos de Palmas, em referência aos galos-de-briga, pois estes "batalham" entre si, tentam "cantar de galo" para conquistar o posto de mais importante para a festa (Raízes, 2018). Cada um dos cinco galos representa uma das cinco regiões de Palmas e, por esse motivo, eles disputam qual deles ocupa o cargo de mais importante para a festa. São eles: o galo Tabokão, que representa a força do masculino, da terra, além de representar na festa a origem da capital a partir do distrito de Taquaruçu, bem como sua tradição; o galo Imperioso, que representa a região do bairro de Aurênys, um dos primeiros distritos da região e, por isso, representa a força do povo na construção de Palmas; o galo Alto, que representa a região de Taquaralto com a força do comércio em Palmas; o galo União, que representa a Vila União, principal bairro da região norte de Palmas. Ele Representa as diversas culturas e forças que se uniram para construir Palmas (Raízes, 2018). Esta região agrega as mais diversas culturas e povos do Brasil, devido ao fato de que foi a região onde os trabalhadores construtores da cidade de Palmas, por não conseguirem moradia no centro da cidade, conseguiram um espaço para se abrigar e construir moradias; e, por fim, o galo Mahanduká, que é representante da região central da capital, simbolizando toda a modernidade dela. O nome do boneco, Mahanduká, significa "gente do centro", de modo que o boneco possui, na sua construção, símbolos retirados do frontispício da principal construção do centro de Palmas, o Palácio Araguaia, construído na Praça dos Girassóis, marcando o centro geográfico da capital (Raízes, 2018). 
comportamento através da repetição, o que implica, automaticamente, uma continuação em relação ao passado. Sempre que possível um passado histórico especifico. [...] contudo a relação mantida com este passado é muitas vezes bastante artificial. [...] Ou seja, elas são reações a situações novas que assumem a forma de referência, ou então estabelecem seu próprio passado através da repetição.

É preciso, então, com base na definição exposta anteriormente, apresentar algumas características da festa que possibilitam a inserção desta nos preceitos de tradição inventada. A primeira questão na qual se deve debruçar é sobre as nítidas regras que regulam as tradições inventadas, neste sentido, as práticas inventadas não ocorrem como aleatoriedade. Os Bonecos Gigantes têm personagens fixos, que seguem organizações muito fechadas, sendo, inclusive, necessárias permissões para poder substituir uma cabeça ou uma roupa de algum boneco. Existem regras que foram construídas pelos criadores da festa, as quais devem ser seguidas e respeitadas por aqueles que com ela se relacionam. Sobre as regras particulares da festa, Mestre Wertemberg diz:

Pra mim aquele cara [o boneco] tem uma ideia que eu tenho pra ele, que ele está representando. [...] Ai até a dificuldade minha de ter feito aquela cabeça, de ter comprado aquele pano, de conseguir aquela roupa, sabe? Até a história do processo que cheguei nele às vezes me toca que eu não quero. Se você me der uma roupa aqui para o boneco eu não vou querer ela (Nunes, 2020).

Existe, portanto, uma série de construções ônticas de significados na festa dos bonecos. Essas regras, embora possam parecer, para os leitores desavisados, muito simplistas, demonstram em si a potência e a necessidade de observação das práticas nas suas particularidades. Na compreensão de que os dados do cotidiano são importantes, os perceptos e os afetos dessas pessoas se manifestam a partir de suas parti-peculiaridades com as festas.

No que se refere à segunda esfera do conceito do Hobsbawm (1990), a saber as relações históricas que a tradição possui com seu passado específico, o criador da festa diz em sua fala que muitas das histórias, mitologias e práticas que auxiliaram a construção da aldeia partem de vivências muito particulares deste ou dos próprios familiares. 
A gente não tinha isso de ficar carregando, ai isso ta ligado a isso, ligado aquilo e tal e tal. Tanto que alguns pressupostos que eu to te contando você pode ver que tem algumas coisas que são bem íntimas nossa, tá ligado a meu filho, tá ligado ao que eu pensei, tá ligado a minha forma de pensar, não tá ligado ah ideia de ah eu criei pra tal coisa (Nunes, 2020).

As relações históricas da festa, portanto, estão ligadas a questões que apenas seus fazedores conhecem, os quais não se importam de contar a quem se dedicar a ouvi-las. As relações místicas, familiares, oníricas constituem e correlacionamse com todos os locais e personagens dentro da festa.

Esses fatos e dizeres coadunam com o fechamento da questão para o Hobsbawm quando ele encerra seu pensamento dizendo que as tradições inventadas são "reações a situações novas que assumem a forma de referência, ou então estabelecem seu próprio passado através da repetição" (Hobsbawn, 1990, p.8). Pode-se perceber essas relações com valores de referências nas práticas da aldeia, quando seu fazedor fala sobre a incredulidade das pessoas com o fato de a tradição ser, de fato, inventada por eles.

Chega um repórter que vem de fora, aí pergunta o que é isso, aí a gente explica que é o Tabokão, os bonecos. Ai o cara começa a endoidar, a dizer que é milenar, que é coisa de comunidade e perguntar quem inventou isso? Foi a gente. Ninguém acredita que foi a gente que inventou (Nunes, 2020).

Percebe-se, no discurso dos fazedores, a percepção da festa dos bonecos gigantes como uma festa inventada. Hobsbawm (1990, p. 9) diz que "A inovação não se torna menos nova por ser capaz de revestir-se facilmente de um caráter de antiguidade" e continua dizendo que é comum "a utilização de elementos antigos na elaboração de novas tradições inventadas para fins bastante originais." Dessa forma, as relações da festa também são apontadas com o conceito de tradição inventada desenvolvido pelo Hobsbawm.

\section{Afetação 4 - A Aldeia TabokaGrande e seu espaço de Pertencimento}

Passa-se aqui a discutir a Aldeia e suas manifestações como esta tradição 
inventada, que foi pensada como um espaço/lugar novo, com a finalidade de seu fazedor conseguir se expressar e se identificar, ou seja, se sentir pertencente. Tal relação torna-se evidente na letra de uma das canções que, nas palavras do Mestre Wertemberg, foi composta para expressar a motivação da criação da Aldeia TabokaGrande. A canção se chama Procura e diz logo em seu início

\author{
Procura - Wertemberg Nunes \\ Andei, andei, andei não pude encontrar \\ um lugar que fosse meu, tive que criar. \\ Às vezes a gente procura um sonho, um lugar \\ Um caminho pra se viver em paz \\ A vida é essa procura, cruzar dos caminhos \\ Que nos ensina como o mar, pra quem quer navegar. \\ Aprendi nos caminhos da vida que amar é sofrer, insistir e \\ querer comungar a alegria e a dor e viver, só viver. \\ Esse é o mundo do amor. \\ Tem um tempo de plantar, tem um tempo de colher \\ Tem um tempo que dá tudo, noutro tempo nada faz \\ Equilibrando o tempo, aprendi viver em paz.
}

O grifo serve para que se possa perceber como o Mestre Wertemberg entende a Aldeia TabokaGrande: como um espaço que ele "teve que criar" devido à realidade de não encontrar um espaço onde pudesse se sentir pertencente. Além disso, também pelas especificidades técnicas do espaço e pela forma como Mestre Wertemberg gostaria que seu teatro fosse realizado, foi preciso criar este espaço. Sobre isso, ele diz:

Eu queria imaginar um lugar meio assim, na natureza, que você pudesse
ter o ambiente natural para criar o espetáculo, pra você fazer a coisa,
porque eu queria teatro de rua. Então por isso que ao chegar aqui, quando
eu comecei mais a ter a ideia do que fazer, eu primeiro tentei fazer um
lugar ali embaixo pra ser este lugar [...] A necessidade deste lugar para
que eu tivesse um lugar que eu pudesse planejar, pudesse experimentar
e que eu pudesse criar o espetáculo" (Nunes, 2020).

O que se percebe aqui é a necessidade de construção de um espaço para identificação, a partir da percepção de que esteticamente e ontologicamente Mestre Wertemberg não se encontrava em espaços convencionais. Devido a isso, através das criações para a Aldeia, foi preciso passar a justificar e fundamentar as suas práticas, tal como ele aponta "Eu acabei tendo que criar as provas [...] criando 
as próprias referências pra eu poder dizer aquilo, pra provar que aquilo era aquilo" (Nunes, 2020).

Percebe-se, portanto, que tão importante quanto demonstrar teoricamente que as brincadeiras realizadas pela Aldeia, pela família Tawera e pelo Mestre Wertemberg são tradições inventadas é ouvir seus fazedores, que apresentam diretamente em seus discursos o fato de a festa ter sido criada por eles: "Foi a gente. Ninguém acredita que foi a gente que inventou" (Nunes, 2020).

Esse espaço, que foi inventado pelo Mestre Wertemberg, permite entender e afirmar a hipótese inicial de que a festa dos Bonecos Gigantes foi inventada para propiciar a seus fazedores um espaço de pertencimento, simbólico e espacial. Há, portanto, a necessidade de reunir-se em tribos, alterar o ambiente para dele apropriar-se como seu espaço de aquilombamento.

Encerra-se aqui este texto, mas de uma forma não muito comum. Traz-se, com o intuito de fechar esta breve revisão, a fala do meu principal colaborador, Mestre Wertemberg Nunes, na letra de sua canção Ladainha da Humanação. Para finalizar, é importante lembrar sempre de que as histórias das pessoas são sua vida, e a vida é muito importante para não ser colocada em primeiro plano. Segue a letra da canção:

\footnotetext{
A história do homem

Está na palma da tua mão

Nos sonhos e nos festejos

Nos costumes e tradições

Toda mão é igual

O traçado que é diferente

Cada risco é um pedaço

da história de sua gente.

A história do homem

Vem da batalha do presente

Está no passado guerreiro

O futuro de sua gente

Todo guerreiro é igual

O destino que é diferente

Cada conquista é um pedaço

Na história de sua gente

Toda cidade é igual

Cada rua que é diferente

Cada casa é um pedaço

Da história de sua gente

Cada praça é um pedaço
} 
Da história de sua gente

Cada morro é um pedaço

Da história de sua gente

Cada canto um pedaço

Da história de sua gente

Eh viva meu deus,

Eh viva meu deus, Camará

Eh viva aos Tawera...

\section{Referências}

BALLESTRIN, Luciana. América Latina e o giro decolonial. Revista Brasileira de Ciência Política, Brasília, n. 11, p.89-117, maio - agosto de 2013.

BAUMAN, Zygmunt. Modernidade Líquida. Rio de janeiro: Jorge Zahar, 2001.

BEZERRA, N. A. A migração em Palmas/TO: a felicidade no imaginário social. Porto Nacional, TO: UFT, 2013.

BIÃO, Armindo. A vida ainda breve da Etnocenologia: uma nova perspectiva transdisciplinar para as artes do espetáculo. Cátedra de Artes, n. 10, 2011.

Faculdad de Artes. Pontifícia Universidad Católica de Chile, 2011. Disponível em: http://catedradeartes.uc.cl/pdf/catedra\%2010/la\%20aun\%20breve\%20vida\%20de \%2 Ola\%20estnoescenologia.pdf

BIÃO, Armindo. Um léxico para a Etnocenologia: proposta preliminar. In: BIÃO, Armindo. Etnocenologia e a cena baiana: textos reunidos, Salvador: P\&A Gráfica e Editora, 2009, p.33-44. Disponível:

http://www.teatro.ufba.br/gipe/arquivos_pdf/ETNOCENOLOGIA1.pdf.

BIÃO, Armindo. Etnocenologia e a cena baiana: textos reunidos. Salvador: P\&A Editora, 2009.

CASTRO-GOMEZ, Santiago. La hybris del punto cero: ciencia, raza e ilustración en la Nueva Granada, Bogota: Editorial Pontificia Universidad Javeriana, 2005.

HOBSBAWM, Eric; RANGER, Terence. A invenção das tradições. Rio de Janeiro: Paz e Terra, 1990.

MAIA, Tatiana. Modos de pertencimento, fontes de guerra: nacionalismo e identidade religiosa nos séculos XX e XXI. Revista História: Debates e Tendências, v. 19, n. 4, p.666-680, 23 dez. 2019.

MAFFESOLI, Michel. Pós-modernidade. Comunicação e Sociedade, [S. l.], v. 18, p. 21-25, 2010. Disponível em:

https://revistacomsoc.pt/index.php/revistacomsoc/article/view/1471. Acesso em: 18 dez. 2020. 
MAFFESOLI, Michel. O Tempo das Tribos - O declínio do individualismo nas sociedades de massa. Rio de Janeiro: Forense Universitária, 2006.

MOURAO, Ada Raquel Teixeira; CAVALCANTE, Sylvia. O processo de construção do lugar e da identidade dos moradores de uma cidade reinventada. Estudos de Psicologia, Natal, v.11, n.2, p.143-151, 2006.

NUNES, Wertemberg. Vida, Obra e Aldeia TabokaGrande. Autor Adailson Costa dos Santos. Entrevista concedida para realização de pesquisa de doutoramento do pesquisador Adailson Costa dos Santos. Online: Via Google Meet, 2020.

PERTENCER. In: DICIONÁRIO da língua portuguesa. Lisboa: Priberam Informática, 2020. Disponível em: http://www.priberam.pt/dlDLPO. Acesso em: 12 dez. 2020.

RAÍZES do Tocantins. Taquaruçu - Bonecos Gigantes da Aldeia TabokaGrande. 2018. Disponível em: https://www.youtube.com/watch?v=viJKbo2QsTk

SOUZA, Bárbara Oliveira. Aquilombar-se: panorama histórico, identitário e político do Movimento Quilombola Brasileiro. 2008. Dissertação (Mestrado e Antropologia Social) - Universidade de Brasília, Brasília, 2008.

VELOSO, Graça. Bendito, divino, consagrado: velhos mestres e novos foliões. Brasília: Trampolim, 2018.

ZAOUAL, H. Nova economia das iniciativas locais: uma introdução ao pensamento pós-global. Tradução de Michel Thiollent. Rio de Janeiro: DP\&A: Consulado Geral da França/COOPE/UFRJ, 2006. 